\title{
Ocular surface microcirculation is better preserved with pulsatile versus continuous flow during cardiopulmonary bypass-An experimental pilot
}

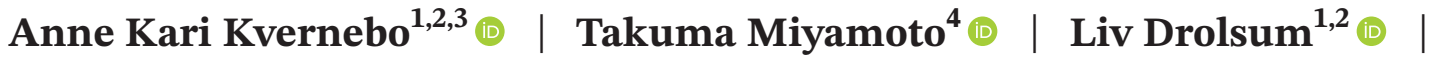 \\ Morten Carstens Moe ${ }^{1,2} \odot$ | Svein-Erik Måsøy ${ }^{5}$ | Gengo Sunagawa ${ }^{4}$ | \\ Raymond Dessoffy $^{4}$ | Jamshid H. Karimov ${ }^{4}{ }^{\oplus}$ | Kiyotaka Fukamachi ${ }^{4}{ }^{4}$ | \\ Knut Kvernebo ${ }^{2,3,5}$
}

${ }^{1}$ Department of Ophthalmology, Oslo University Hospital, Oslo, Norway

${ }^{2}$ Institute of Clinical Medicine, Faculty of Medicine, University of Oslo, Oslo,

Norway

${ }^{3}$ The Circulation Laboratory,

Department of Cardiothoracic Surgery,

Oslo University Hospital, Oslo, Norway

${ }^{4}$ Department of Biomedical

Engineering, Cleveland Clinic Lerner

Research Institute, Cleveland, Ohio,

USA

${ }^{5}$ ODI Medical AS, Oslo, Norway

\section{Correspondence}

Anne Kari Kvernebo, Department of Ophthalmology, Oslo University

Hospital, Ullevål, Box 4956 Nydalen,

$\mathrm{N}-0424$ Oslo, Norway.

Email: b24427@ous-hf.no

\section{Funding information}

The South-Eastern Norway Regional Health Authority is funding the $\mathrm{PhD}$ fellowship of Anne Kari Kvernebo, grant number 23439. The study at Cleveland clinic was funded by a research grant from VentriFlo, Inc (Pelham, NH, USA). Funding contributors have not been involved in study design; collection, analysis and interpretation of data; writing of the report or decision to submit the article for publication

\begin{abstract}
Background: Non-pulsatile cardiopulmonary bypass (CPB) may induce microvascular dysregulation. In piglets, we compared ocular surface microcirculation during pulsatile versus continuous flow $(\mathrm{CF})$ bypass.

Methods: Ocular surface microcirculation in small tissue volumes $\left(\sim 0.1 \mathrm{~mm}^{3}\right)$ at limbus (high metabolic rate) and bulbar conjunctiva (low metabolic rate) was examined in a porcine model using computer assisted video microscopy and diffuse reflectance spectroscopy, before and after 3 and $6 \mathrm{~h}$ of pulsatile ( $n=5$ piglets) or $\mathrm{CF}$ ( $n=3$ piglets) CPB. Functional capillary density, capillary flow velocity and microvascular oxygen saturation were quantified.

Results: At limbus, velocities improved with pulsatility $(p<0.01)$ and deteriorated with $\mathrm{CF}(p<0.01)$. In bulbar conjunctiva, velocities were severely reduced with CF $(p<0.01)$, accompanied by an increase in capillary density $(p<0.01)$. Microvascular oxygen saturation decreased in both groups.

Conclusion: Ocular surface capillary densities and flow patterns are better preserved with pulsatile versus $\mathrm{CF}$ during $6 \mathrm{~h}$ of $\mathrm{CPB}$ in sleeping piglets.
\end{abstract}

\section{K E Y W O R D S}

bulbar conjunctiva, capillaries, capillary flow velocity, functional capillary density, limbus, mechanical circulatory support, microcirculation, microvascular oxygen saturation, ocular surface, ODIN concept, pulsatile versus continuous flow 


\section{1 | INTRODUCTION}

Continuous flow (CF) pumps for cardiopulmonary bypass $(\mathrm{CPB})$ are reliable and cost effective, and mortality rates related to standard open-heart surgical procedures are low. However, in patients supported with CF pumps for days, that is, during extra corporeal membrane oxygenation (ECMO), morbidity and mortality rates remain high both during and for months following treatment. ${ }^{1-3}$ Biological evolution has favored pulsatile flow (PF) in circulatory systems among vertebrates, ${ }^{4}$ but $\mathrm{CF}$ pumps are still preferred for $\mathrm{CPB}$ and $\mathrm{ECMO}$ despite evidence that $\mathrm{PF}$ better preserves microcirculation in end organs. ${ }^{5,6}$

Circulatory failure occurs when the respiratory and cardiovascular systems supply insufficient amounts of oxygen to meet the metabolic demands of all the cells of the body. Clinical medicine lacks technologies for direct assessments of oxygen delivery from the microcirculation to cells. Macro- and microvascular parameters are known to be dissociated during circulatory failure ${ }^{7}$ and there is a compelling need for new methods to monitor microcirculatory function. ${ }^{8}$

The non-invasive oxygen delivery index (ODIN) concept for assessments of microvascular function, includes technologies (computer assisted video microscopyCAVM and diffuse reflectance spectroscopy-DRS), data acquisition protocols and analyses that can be used for estimating the capacity for oxygen delivery from the microcirculation to cells in volumes of $\sim 0.1 \mathrm{~mm}^{39-15}$ by quantifying functional capillary density (FCD), capillary flow velocities (CFV) and microvascular oxygen saturation $\left(\mathrm{SmvO}_{2}\right)$.

A correlation between cerebral and ocular surface microcirculation (i.e., conjunctiva) has previously been demonstrated both in animals and in humans. ${ }^{16,17}$ Arterial ophthalmic supply derives from both the internal carotid artery via the ophthalmic artery, and from the external carotid artery via the temporal and maxillary arteries. ${ }^{18}$ Ocular surface microcirculation may therefore represent a surrogate measure of brain perfusion in patients with systemic circulatory failure. The limbus, a metabolically active circumferential transition zone $(\sim 0.6 \mathrm{~mm})$ between the avascular cornea and bulbar conjunctiva has a high concentration of stem cells continuously regenerating the corneal epithelium. The bulbar conjunctiva is assumed to have more scattered stem cells, a lower metabolic rate and vessels transport oxygenated blood to reach limbal capillaries. In sleeping piglets, we have shown that the ODIN concept can be used to estimate oxygen delivery to conjunctival cells, and also that the microvascular capacity to deliver oxygen was greater at limbus than the bulbar conjunctiva, compatible with a higher metabolic rate at limbus. ${ }^{12}$
In the present study, our hypothesis was that ocular surface microcirculatory function is better preserved with $\mathrm{PF}$ as compared with a CF pump. During 6-h CPB, we used the ODIN concept to compare effects on limbal and bulbar conjunctival microcirculation in sleeping piglets assigned to either PF or CF.

\section{$2 \mid$ MATERIAL AND METHODS}

The ODIN concept was used for ocular surface measurements at baseline (before skin incision), $3 \mathrm{~h}$ and $6 \mathrm{~h}$ in eight healthy female Yorkshire piglets $(44 \pm 4 \mathrm{~kg})$ supported with PF (VentriFlo True Pulse Pump ${ }^{\circledR}$, Design Mentor Inc, Pelham, NH, USA) $(n=5)$ or CF (Rotaflow ${ }^{\circledR}$, Maquet Holding BV \& Co. KG, Rastatt, Germany) $(n=3)$ pumps.

During data collection, each recorded file was labeled with a code. The analyzer was blinded to type of heart pump and time of recording. The study protocol (20161659) was approved by Institutional Animal Care and Use Committee at Cleveland Clinic. The piglets were treated in compliance with the Guide for Care and Use of Laboratory Animals and institutional guidelines.

\subsection{Preoperative piglet preparation}

The piglets were quarantined and monitored at the laboratory facility for at least three days and fasted $12 \mathrm{~h}$ before surgery. Premedication-xylazine $(2 \mathrm{mg} / \mathrm{kg}$, IM) and ketamine $(20 \mathrm{mg} / \mathrm{kg}$, IM) — was administered and vital signs (respiratory rate, appetite, general condition) monitored. Anesthesia was induced by propofol $(1 \mathrm{mg} / \mathrm{kg}, \mathrm{IV})$ or buprenorphine $(0.05 \mathrm{mg} / \mathrm{kg}$, IV), and was maintained throughout the experiment by volatile isoflurane (1.0$3.0 \%$ ). Fraction of inspired oxygen was set to $80 \%$ before $\mathrm{CPB}$ and lowered to $50 \%$ during $\mathrm{CPB}$. To prepare the neck, groin, and chest for open chest surgery, the piglets were fixated in a supine position with attached ECG leads to the extremities. Lidocaine $(<2 \mathrm{mg} / \mathrm{kg} / \mathrm{h}$ IV) was injected to prevent ventricular arrhythmia. Arterial monitoring lines were inserted in the carotid artery and a venous pressure line in the jugular vein.

\subsection{CPB procedure and sampling of blood gas}

The pericardium was opened following a median sternotomy. A pulmonary artery flow probe was used to measure cardiac output and to control that flow was kept at $0 \mathrm{~L} / \mathrm{min}$ during CPB. Cannulas were inserted through the right 
atrial appendage into the ascending aorta and the inferior vena cava (22 Fr EOPA ${ }^{\circledR}$ [elongated one-piece] Arterial Cannula, Medtronic Perfusion Systems, Minneapolis, MN, or 21 Fr Arterial Cannula, Edwards Lifesciences, Irvine, CA and 34-46 Fr or 29-37 Fr MC2 Two-Stage Cannula, Medtronic Perfusion Systems, Brooklyn Park, $\mathrm{MN})$. A vent tube, inserted in the left atrium or ventricle, prevented ejection of blood.

After heparin (500 U/kg, IV) was administered and when activated clotting time exceeded $450 \mathrm{~s}$, CPB was engaged at a flow rate of $50 \mathrm{ml} / \mathrm{kg} / \mathrm{min}$ throughout the procedure. One of the following oxygenators were used in the circuit; Quadrox (Maquet Holding BV \& Co. KG, Rastatt, Germany), Affinity Fusion (Medtronic, Minnesota, USA) or Capiox (Terumo Cardiovascular Systems, Tokyo, Japan). Vasoactive agents were not administered during CPB. Arterial blood gas samples were drawn hourly. After $6 \mathrm{~h}$ on CPB under deep anesthesia (isoflurane 5\%), an additional dose of heparin (500 U/kg, IV) was administered. The piglets were sacrificed by a lethal dose of potassium chloride (2.5-3.5 mEq/kg, IV).

\section{3 | Microcirculatory measuring techniques, parameters and recording procedures}

The eyelids of the left eye were retracted by sutures during measurements and closed between recordings. Saline was applied to maintain a moist ocular surface between measurements.

Microvascular data from the limbal and bulbar conjunctiva was captured with the ODIN concept. ${ }^{12}$ In brief, films of $20 \mathrm{~s}$ duration were recorded by CAVM with a $300 \times$ magnification lens attached to a digital microscope (Optilia, D1, Instruments AB, Sollentuna, Sweden) with autofocus, $1.13 \mathrm{~mm} \times 0.7 \mathrm{~mm}$ field of view, frame rate 7 frames/s and image resolution $1920 \times 1080$ pixels. At least four film sequences from each conjunctival region were recorded at baseline, and at $3 \mathrm{~h}$ and $6 \mathrm{~h}$ thereafter.

Capillaries, identified as visible blood vessels $<20 \mu \mathrm{m}$, which crossed six parallel grid lines separated by $100 \mu \mathrm{m}$, were counted. FCD was expressed as capillary crossings/ $\mathrm{mm}$ line. $\mathrm{CFV}$ was determined at each crossing according to a previously defined 6-category velocity scale ranging from category 0 (no flow) to category 5 (brisk flow). ${ }^{12}$

To measure $\mathrm{SmvO}_{2}$ in tissue volumes of $\sim 0.1 \mathrm{~mm}^{3}$, we used DRS; a spectrometer (AvaSpec-2048-2, Apeldoorn, The Netherlands) with a tungsten halogen light source (AvaLight-HAL, Apeldoorn, The Netherlands) and spectral range of $450-800 \mathrm{~nm}$. The fiber optic probe was calibrated against a white polytetrafluorethylene tile (WS-2, Avantes, The Netherlands) before each set of recordings.
The positioning of the DRS probe was not sufficiently precise to discriminate between limbal and bulbar recordings.

The equipment was moved slightly between each recording to capture different measuring volumes.

\section{4 | Data analysis and statistics}

Custom-made software (EyeSoft version 1.0, ODI Medical, Oslo, Norway) was used to analyze CAVM films and to calculate DRS-determined $\mathrm{SmvO}_{2} \cdot{ }^{12}$

Statistical analyses were conducted in SPSS version 26 (SPSS Inc, Chicago, Illinois, USA). Continuous variables are expressed as mean $\pm \mathrm{SD}$. An independent samples $t$ test was used to compare $\mathrm{CF}$ and PF pumps for the FCD and $\mathrm{SmvO}_{2}$ parameters. Graphical displays of these data are box-whisker plots presenting median, 25th and 75th percentiles, range and outliers. A chi square test was used to compare categories for CFV. A $p$-value $<0.05$ was considered statistically significant.

\section{3 | RESULTS}

During this experiment, mean arterial pressure for the pumps varied between $33-38 \mathrm{~mm} \mathrm{Hg}$ (PF) and 30-39 mm $\mathrm{Hg}(\mathrm{CF})$ with a pulse pressure between 23-34 $\mathrm{mm} \mathrm{Hg}(\mathrm{PF})$ and 4-5 $\mathrm{mm} \mathrm{Hg}(\mathrm{CF})$. A detailed presentation of hemodynamics is given elsewhere. ${ }^{19}$ Microscopy films and DRS spectra were collected without adverse events. Numbers, location and time of analyzed capillaries and spectra are given in Table 1.

\section{1 | Capillary flow velocity}

The majority of CFV-scored capillaries were in category 0 (no flow) and $3(\mathrm{CF})$. Category 4 (rapid flow) was rarely observed $(<4 \%$ of measurements) and category 5 (brisk flow) was never observed.

In limbal recordings, the PF piglets decreased category 0 and increased category $3 \mathrm{CFV}$-scores during the $6 \mathrm{~h}$ experiment, $p<0.01$ (Figure 1A,C). The opposite CFV pattern was seen in CF piglets, $p=0.01$ and $p<0.01$ (Figure 1B,D). In bulbar conjunctiva, category 3 decreased and category 0 increased for both pumps $(p<0.01)$, but only CF piglets had critically low CFV after 6 h (Figure 1E-H).

\section{$3.2 \mid$ FCD}

At baseline, ocular surface FCD of all piglets was higher at limbus $(11.3 \pm 3.0)$ as compared with bulbar conjunctiva 
TABLE 1 Total numbers of examined capillaries/spectra for assessment of each parameter

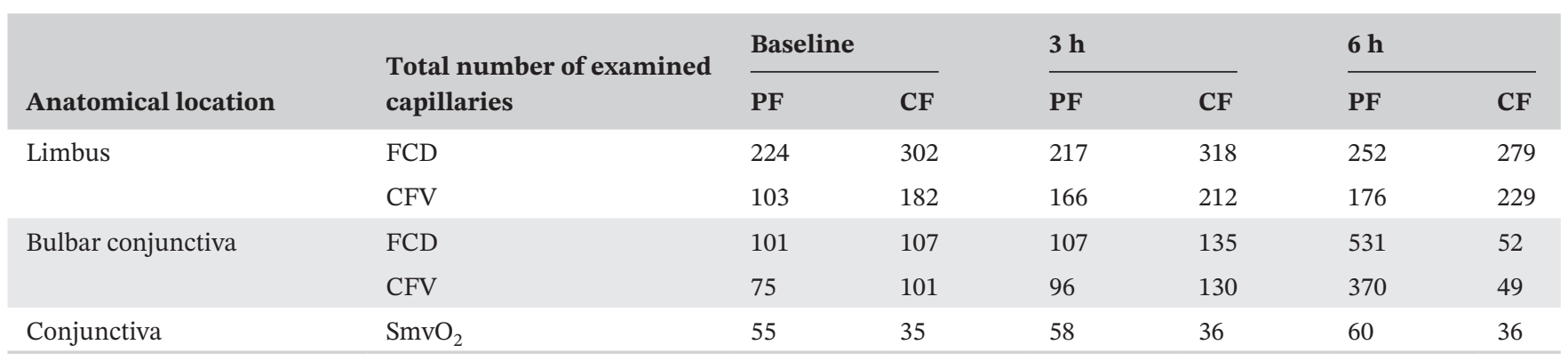

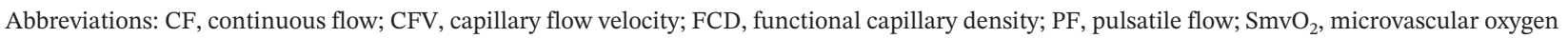
saturation.

(7.1 \pm 2.8$), p<0.01$. Piglets supported by PF had a stable FCD throughout the study both at limbus and in bulbar conjunctiva, whereas piglets aided by $\mathrm{CF}$ increased bulbar conjunctival FCD after 6 h, $p<0.05$ (Figure 2B).

\section{3 | DRS}

Average arterial oxygen saturation for all measurements in piglets throughout the experiment was $99 \%$ and no measurement was below 96\%. Ocular surface $\mathrm{SmvO}_{2}$ decreased over time independent of pump (Figure 3). No significant differences were seen between the two pumps at baseline, 3 and $6 \mathrm{~h}$.

\section{4 | DISCUSSION}

In the current study we utilize the ODIN concept to assess ocular surface microcirculation in sleeping piglets assigned to PF or CF pumps during $6 \mathrm{~h}$ of CPB. Piglets supported on $\mathrm{PF}$ had a higher percentage of capillary category 3 flow (optimal velocity) both at limbus and in bulbar conjunctiva as compared with $\mathrm{CF}$ (Figure $1 \mathrm{C}$ vs. 1D, and Figure $1 \mathrm{G}$ vs. Figure $1 \mathrm{H}$ ) after $3 \mathrm{~h}$. These differences were even more pronounced after $6 \mathrm{~h}$. Ocular surface FCD was unaffected in $\mathrm{PF}$ piglets, while $\mathrm{CF}$ triggered increased FCD compatible with capillary recruitment, after $6 \mathrm{~h}$ (Figure 2B), possibly caused by hypoxia.

Oxygen delivery from capillaries is vital for all cells, and is dependent on an interaction between several factors, including our set of parameters. Low CFV facilitates oxygen extraction (i.e., equilibration of oxygen between the erythrocytes and the surrounding tissue), due to long capillary erythrocyte transit time, but since few erythrocytes pass through the capillary network, oxygen delivery is low. Higher CFV shortens transit- and equilibration time for oxygen extraction from each erythrocyte-the capillary serves as a physiological arteriovenous shuntbut oxygen delivery is maintained due to the large number of erythrocytes passing through the capillary.
In healthy humans using the present velocity scale, category $3 \mathrm{CFV}$ is seen in $>80 \%$ of skin nutritive papillary capillaries. ${ }^{13}$ Low velocities at baseline in this study may be related to the examined tissue (ocular surface) or the experimental model (supine position of piglets and administered anesthetic drugs). At limbus, category $3 \mathrm{CFV}$ increased and category 0 decreased in the PF piglets over time (Figure $1 \mathrm{~A}, \mathrm{C}$ ), meaning that $\mathrm{CFV}$ optimized throughout the $6 \mathrm{~h}$ on CPB. The opposite CFV patterns were observed for the $\mathrm{CF}$ piglets (Figure 1B,D), indicating that oxygen delivery was compromised. In bulbar conjunctiva, percentages of capillaries in category 3 after $6 \mathrm{~h}$ were acceptable for PF, and critically low for CF (Figure 1G,H).

In the present study, limbal FCD at baseline was higher in the CF piglets as compared with the PF piglets (Figure 2A), but no changes between the two groups were seen at limbus for the next $6 \mathrm{~h}$ on pump. In bulbar conjunctiva the two groups had similar FCD, except for an increase in CF piglets after $6 \mathrm{~h}$ (Figure 2B). This recruitment of capillaries was coexisting with the mentioned critically low $\mathrm{CFV}$ in $\mathrm{CF}$ piglets (Figure $1 \mathrm{~F}, \mathrm{H}$ ) and is interpreted as a compensatory mechanism to maintain oxygen delivery.

Decreased $\mathrm{SmvO}_{2}$ observed in both groups after 3 and $6 \mathrm{~h}$ indicates increased tissue oxygen extraction (arterial oxygen saturation- $\mathrm{SmvO}_{2}$ ). Arterial oxygen saturation was $>96 \%$ throughout the experiment, but both pumps in this model failed to maintain unaltered $\mathrm{SmvO}_{2}$. The limbus is $<1 \mathrm{~mm}$ wide, and we did not have sufficient precision of probe placement to discriminate between limbal and bulbar recordings. We believe that the greater part of recorded $\mathrm{SmvO}_{2}$ values (Figure 3) represent bulbar conjunctiva and that the results are inconclusive with regards to oxygen extraction at limbus (high metabolic demand).

Worldwide state-of-the-art CPB and ECMO are conducted with $\mathrm{CF}$ pump despite publications indicating that $\mathrm{PF}$ is superior to $\mathrm{CF} .{ }^{6,17,20-24}$

Various study designs, methods and endpoints have been used to study microvascular function related to $\mathrm{CF}$ or PF pumps. Studies using side-stream dark field imaging or orthogonal polarization spectral imaging state that sublingual FCD, perfused vessel density and proportion 
FI G URE 1 Capillary flow velocity at limbus (A-D) and bulbar conjunctiva (E-H). Dots represent percentage of all recordings for each pump at baseline, three and six hours. CF, continues flow; $\mathrm{PF}$, pulsatile flow

\section{Limbus PF}

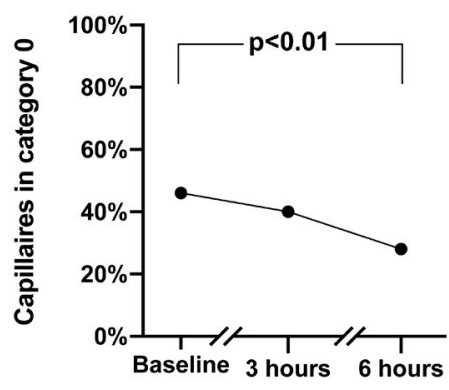

(A)

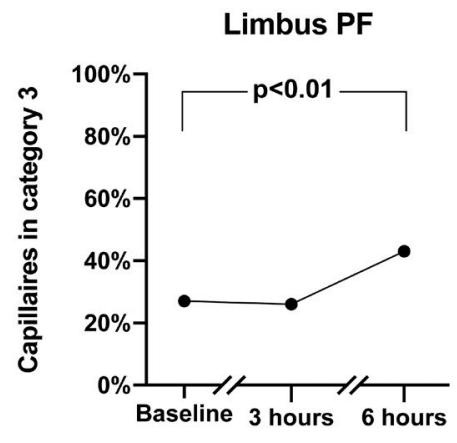

(C)

Bulbar conjunctiva PF

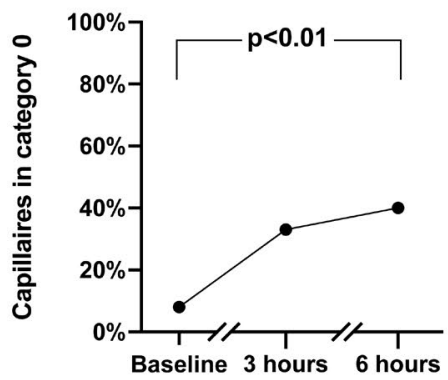

(E)

Bulbar conjunctiva PF

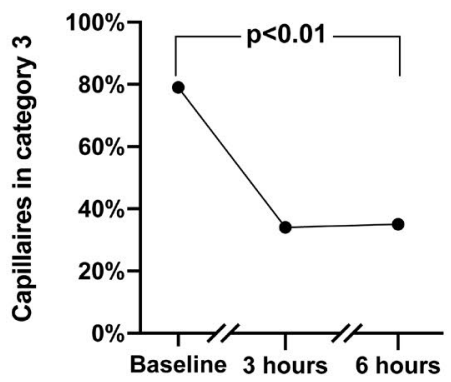

(G)
Limbus CF

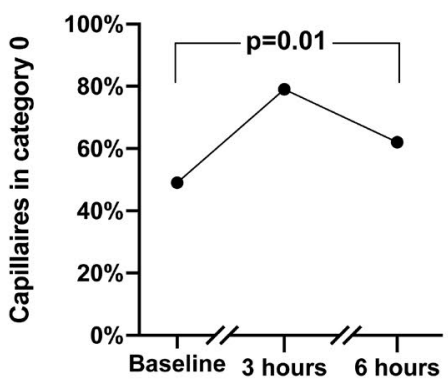

(B)

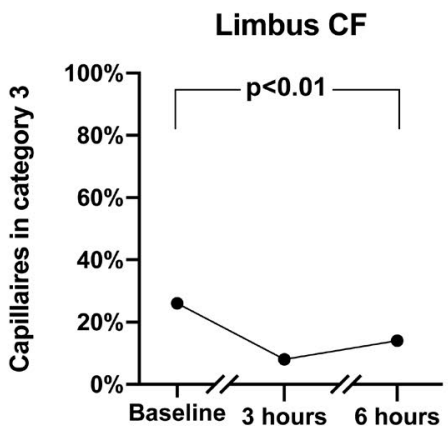

(D)

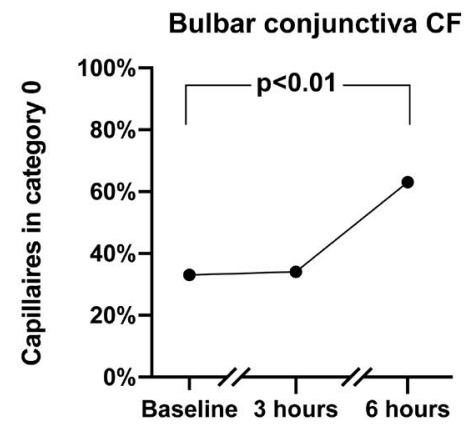

(F)

Bulbar conjunctiva CF

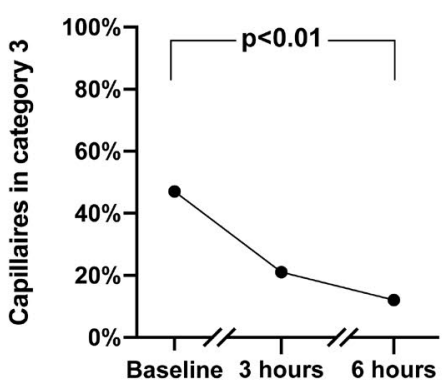

(H) of perfused vessels worsen during $\mathrm{CPB}$, but are inconclusive regarding the significance of pulsatility. ${ }^{25}$ Zhao et al recently showed that bulbar conjunctival microcirculation, examined in our study, better reflects perfusion in the central nervous system as compared with sublingual mucosa. ${ }^{17}$
Frequency of complications related to $\mathrm{CPB}$ rise when surgery exceeds $180 \mathrm{~min} .{ }^{26}$ In the present study, changes in microvascular function in favor of PF developed between 3 and $6 \mathrm{~h}$, while studies failing to demonstrate benefits of PF, often are limited to less than $3 \mathrm{~h}$ on pump. ${ }^{27}$ Our findings correspond with the clinical 


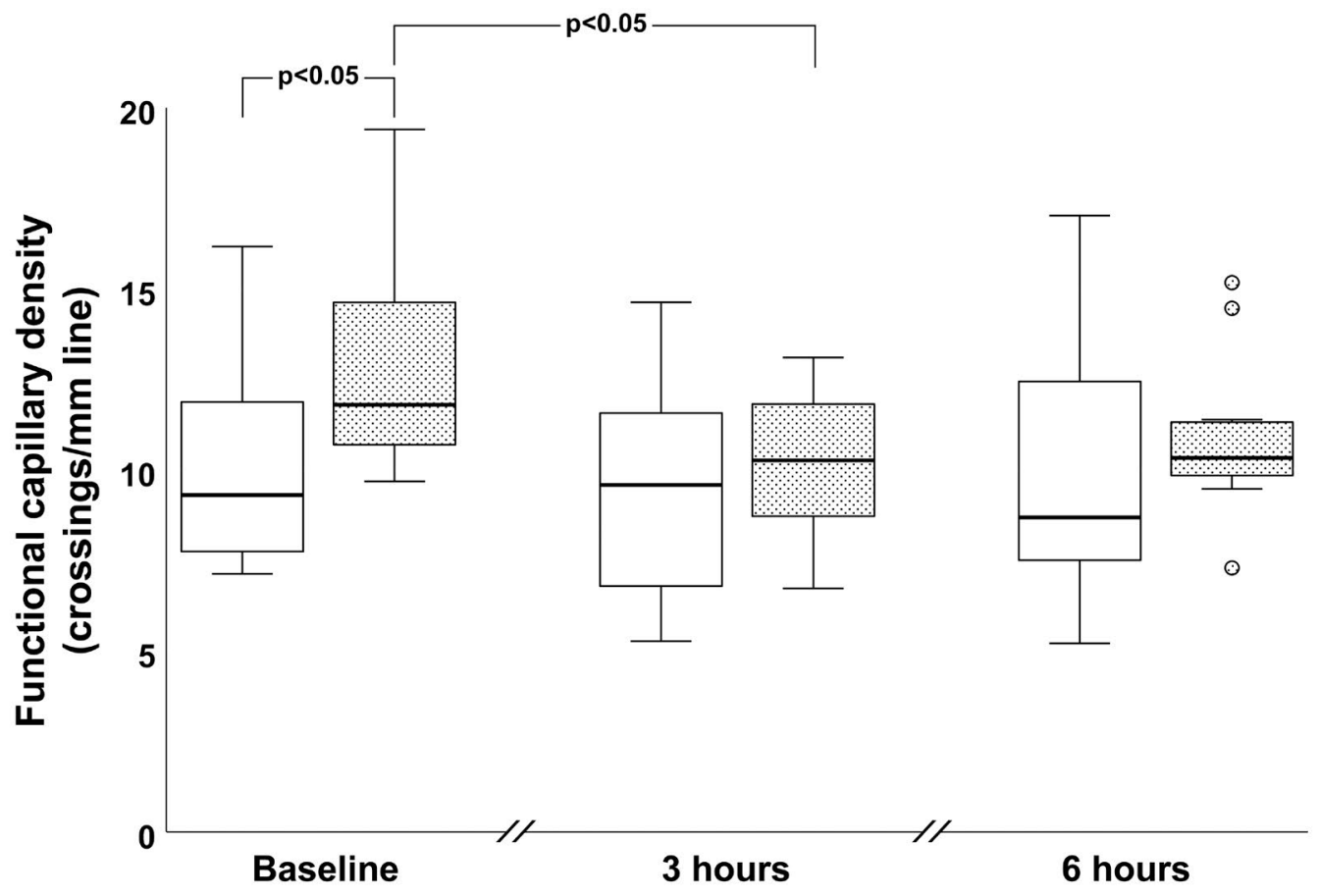

(A)
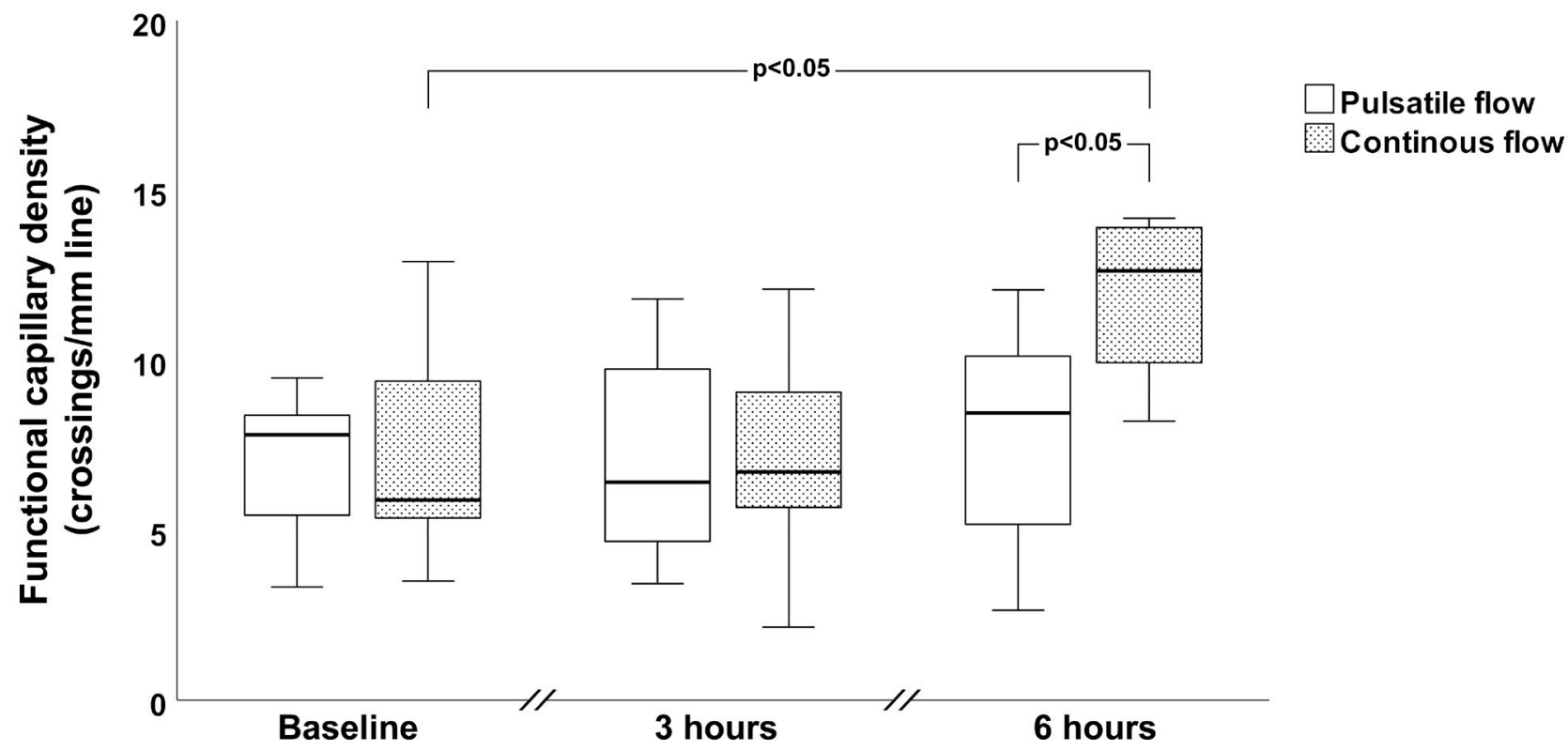

(B)

F I G U RE 2 Functional capillary density at limbus (A) and bulbar conjunctiva (B) in piglets supported by pulsatile and continuous flow

experience that short term procedures (e.g., uncomplicated $\mathrm{CPB}$ ) have good outcomes, while long term $\mathrm{CF}$ ECMO treatment is associated with high morbidity and mortality rates. ${ }^{1-3}$

There are some important limitations to this study. Administered drugs and supine posture may have affected the results. In addition, sample sizes differed between the two groups (five PF piglets vs. three CF piglets). A number of films also had inferior quality and could not be analyzed. This study is only the second report of ocular surface ODIN measurements, and both handling of the equipment and the analyzing platform could be refined.

In conclusion, results in this study indicate that ocular surface capillary densities and flow patterns are better preserved in piglets supported by $\mathrm{PF}$, as compared with $\mathrm{CF}$ during $6 \mathrm{~h}$ of CPB. 


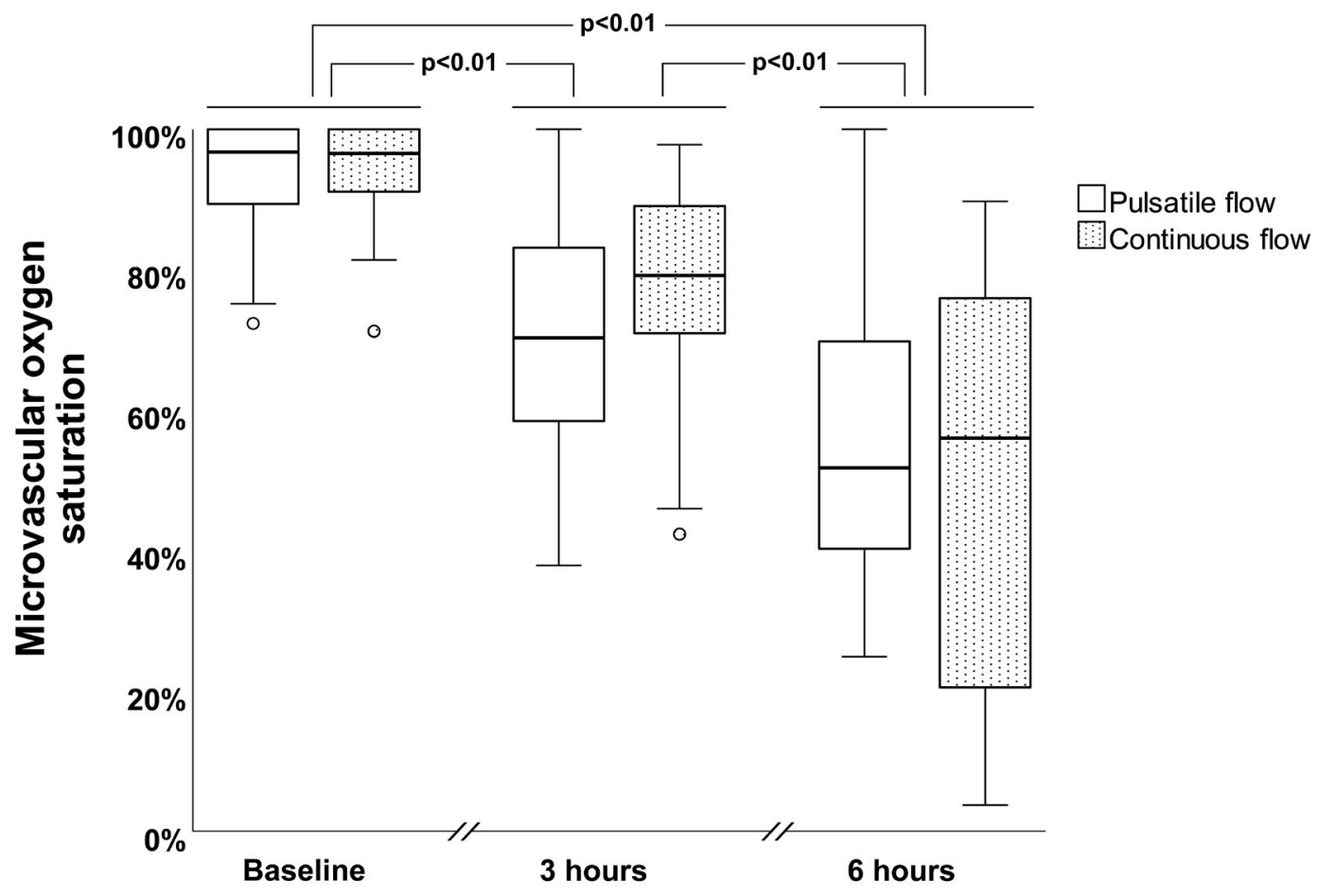

F I G URE 3 Microvascular oxygen saturation piglets at baseline, three and six hours

\section{ACKNOWLEDGEMENTS}

Professor emeritus of medical statistics, University of Oslo, Leiv Sandvik is consulted regarding statistical evaluation. Geir Aksel Qvale assisted with graphical layout.

\section{CONFLICT OF INTEREST}

The ODIN concept is patented in Japan, and a patent is pending in USA and Europe. Knut Kvernebo is founder, shareholder and currently CMO of ODI Medical AS. Måsøy SE is shareholder in ODI Medical. Knut Kvernebo and Anne Kari Kvernebo are related. ODI Medical AS has provided the analysis platform used in this study. Remaining authors have no financial conflicts of interest.

\section{AUTHORS CONTRIBUTIONS}

All authors contributed to the study conception and design. Material preparation and data collection were performed by Takuma Miyamoto, Raymond Dessoffy, Kiyotaka Fukamachi, Anne Kari Kvernebo, Knut Kvernebo. File analyses were performed by Anne Kari Kvernebo, Knut Kvernebo and Svein-Erik Måsøy. All authors participated in data interpretation. The draft of the manuscript was written by Anne Kari Kvernebo. All authors commented, read and approved the final manuscript.

\section{ORCID}

Anne Kari Kvernebo (D) https://orcid. org/0000-0002-9345-1876
Takuma Miyamoto (D) https://orcid. org/0000-0003-4082-8825

Liv Drolsum (1) https://orcid.org/0000-0002-4329-9490

Morten Carstens Moe (D) https://orcid. org/0000-0002-2318-2017

Jamshid H. Karimov (1) https://orcid.

org/0000-0002-0167-0415

Kiyotaka Fukamachi (D) https://orcid. org/0000-0002-4852-8416

Knut Kvernebo (D) https://orcid.org/0000-0001-8262-5829

\section{REFERENCES}

1. Bakhtiary F, Keller H, Dogan S, Dzemali O, Oezaslan F, Meininger D, et al. Venoarterial extracorporeal membrane oxygenation for treatment of cardiogenic shock: clinical experiences in 45 adult patients. J Thorac Cardiovasc Surg. 2008;135:382-8.

2. Doll N, Kiaii B, Borger M, Bucerius J, Krämer K, Schmitt DV, et al. Five-year results of 219 consecutive patients treated with extracorporeal membrane oxygenation for refractory postoperative cardiogenic shock. Ann Thorac Surg. 2004;77(1):151-7; discussion 7.

3. Zangrillo A, Landoni G, Biondi-Zoccai G, Greco M, Greco T, Frati G, et al. A meta-analysis of complications and mortality of extracorporeal membrane oxygenation. Crit Care Resusc. 2013;15:172-8.

4. Moazami N, Dembitsky WP, Adamson R, Steffen RJ, Soltesz EG, Starling RC, et al. Does pulsatility matter in the era of continuous-flow blood pumps? J Heart Lung Transplant. 2015;34:999-1004. 
5. Orime Y, Shiono M, Nakata K-I, Hata M, Sezai A, Yamada H, et al. The role of pulsatility in end-organ microcirculation after cardiogenic shock. ASAIO J. 1992;1996(42):M724-9.

6. Sezai A, Shiono M, Orime Y, Nakata K-I, Hata M, Iida M, et al. Major organ function under mechanical support: comparative studies of pulsatile and nonpulsatile circulation. Artif Organs. 1999;23:280-5.

7. Tafner P, Chen FK, Rabello RF, Corrêa TD, Chaves RCF, Serpa AN. Recent advances in bedside microcirculation assessment in critically ill patients. Rev Bras Ter Intensiva. 2017;29:238-47.

8. Martini R. The compelling arguments for the need of microvascular investigation in COVID-19 critical patients. Clin Hemorheol Micro. 2020;75:27-34.

9. Awan ZA, Häggblad E, Wester T, Kvernebo MS, Halvorsen PS, Kvernebo K. Diffuse reflectance spectroscopy: Systemic and microvascular oxygen saturation is linearly correlated and hypoxia leads to increased spatial heterogeneity of microvascular saturation. Microvasc Res. 2011;81:245-51.

10. Fredly S, Fugelseth D, Nygaard CS, Salerud EG, Stiris T, Kvernebo K. Noninvasive assessments of oxygen delivery from the microcirculation to skin in hypothermia-treated asphyxiated newborn infants. Pediatr Res. 2016;79:902-6.

11. Fredly S, Fugelseth D, Wester T, Häggblad E, Kvernebo K. Skin microcirculation in healthy term newborn infants-assessment of morphology, perfusion and oxygenation. Clin Hemorheol Micro. 2015;59:309-22.

12. Kvernebo AK, Miyamoto T, Sporastøyl AH, Wikslund LK, Måsøy S-E, Drolsum L, et al. Quantification of ocular surface microcirculation by computer assisted video microscopy and diffuse reflectance spectroscopy. Exp Eye Res. 2020;201:108312.

13. Sundheim LK, Sporastøyl AH, Wester T, Salerud G, Kvernebo $\mathrm{K}$. Acute skin trauma induces hyperemia, but superficial papillary nutritive perfusion remains unchanged. Microcirculation. 2017;24(7):e12389.

14. Wester T, Awan ZA, Kvernebo TS, Salerud G, Kvernebo K. Skin microvascular morphology and hemodynamics during treatment with veno-arterial extra-corporeal membrane oxygenation. Clin Hemorheol Micro. 2014;56:119-31.

15. Wester T, Häggblad E, Awan ZA, Barratt-Due A, Kvernebo M, Halvorsen PS, et al. Assessments of skin and tongue microcirculation reveals major changes in porcine sepsis. Clin Physiol Funct Imaging. 2011;31:151-8.

16. Schaser K-D, Settmacher U, Puhl G, Zhang L, Mittlmeier T, Stover JF, et al. Noninvasive analysis of conjunctival microcirculation during carotid artery surgery reveals microvascular evidence of collateral compensation and stenosis-dependent adaptation. J Vasc Surg. 2003;37:789-97.

17. Zhao S, Yang Z, Sun P, Wu X, Tang W, Shao F, et al. Conjunctival microcirculation is associated with cerebral cortex microcirculation in post-resuscitation mild hypothermia: a rat model. Microcirculation. 2020;27:e12604.

18. Cotofana S, Lachman N. Arteries of the face and their relevance for minimally invasive facial procedures: an anatomical review. Plast Reconstr Surg. 2019;143:416-26.

19. Miyamoto T, Sunagawa G, Dessoffy R, Karimov JH, Grady P, Naber JP, et al. Hemodynamic evaluation of a new pulsatile blood pump during low flow cardiopulmonary bypass support. Artif Organs. 2021;1-10. https://doi.org/10.1111/aor.14119

20. Ündar A, Wang S, Izer JM, Clark JB, Kunselman AR, Patel S, et al. The clinical importance of pulsatile flow in extracorporeal life support: the Penn State health approach. Artif Organs. 2016;40:1101-4.

21. O'Neil MP, Alie R, Guo LR, Myers ML, Murkin JM, Ellis CG. Microvascular responsiveness to pulsatile and nonpulsatile flow during cardiopulmonary bypass. Ann Thorac Surg. 2018;105:1745-53.

22. Undar A, Masai T, Beyer EA, Goddard-Finegold J, McGarry MC, Fraser CD Jr. Pediatric physiologic pulsatile pump enhances cerebral and renal blood flow during and after cardiopulmonary bypass. Artif Organs. 2002;26:919-23.

23. Karaci AR, Sasmazel A, Aydemir NA, Saritas T, Harmandar B, Tuncel Z, et al. Comparison of parameters for detection of splanchnic hypoxia in children undergoing cardiopulmonary bypass with pulsatile versus nonpulsatile normothermia or hypothermia during congenital heart surgeries. Artif Organs. 2011;35:1010-7.

24. Baba A, Dobsak P, Saito I, Isoyama T, Takiura K, Abe Y, et al. Microcirculation of the bulbar conjunctiva in the goat implanted with a total artificial heart: effects of pulsatile and nonpulsatile flow. ASAIO J. 1992;2004(50):321-7.

25. den Os MM, van den Brom CE, van Leeuwen ALI, Dekker NAM. Microcirculatory perfusion disturbances following cardiopulmonary bypass: a systematic review. Crit Care. 2020;24:218.

26. Madhavan S, Chan S-P, Tan W-C, Eng J, Li B, Luo H-D, et al. Cardiopulmonary bypass time: every minute counts. J Cardiovasc Surg. 2018;59:274-81.

27. Elvevoll B, Lundemoen S, Svendsen ØS, Mongstad A, Grong $\mathrm{K}$, Kvalheim VL, et al. Does roller pump-induced pulsatile CPB perfusion affect microvascular fluid shifts and tissue perfusion? Ann Thorac Surg. 2016;102:564-72.

How to cite this article: Kvernebo AK, Miyamoto T, Drolsum L, Moe MC, Måsøy S-E, Sunagawa G, et al. Ocular surface microcirculation is better preserved with pulsatile versus continuous flow during cardiopulmonary bypass - an experimental pilot. Artif Organs. 2021;00:1-8. https://doi. org/10.1111/aor.14137 